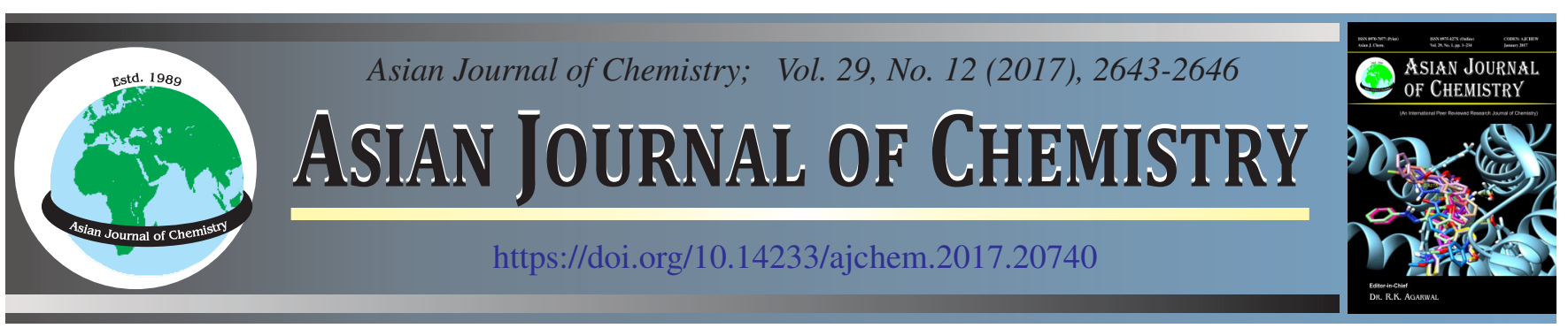

\title{
A Novel Three-Fold Interpenetrating Three-Dimensional Co(II) Coordination Polymer Based on Flexible Bistriazole Ligand: Synthesis, Structure and Magnetic Properties
}

\author{
J.L. Lu, Y.S. XuE*, J. WeI and T. ZHOU
}

School of Chemistry and Chemical Engineering, Yancheng Teachers University, Yancheng 224051, P.R. China

*Corresponding author: Tel: +86 515 88233181; E-mail: xueys1988@163.com; yunshanxue1988@163.com

Keywords: Coordination polymer, 1,4-Bis(1,2,4-triazol-1-yl)butane, Copper complex, Antiferromagnetic.

\section{INTRODUCTION}

In recent years, coordination polymers have attracted a great deal of interest not only owing to their regulated and interesting structural topologies but also because of their potential applications in the fields of ion-exchange, catalysis, photoluminescence, magnetism and gas storage [1-6]. Generally, the assembly of coordination polymer is mainly affected by the combination of a few factors such as temperature, the neutral ligands, the organic anions, the metal atoms, etc. [7-9]. Among these factors, selecting appropriate organic ligand plays a vital role in the construction of coordination polymers with distinctive structures. The flexible bis(triazole) ligands as important build blocks are frequently used in constructing coordination polymers because they can adopt different conformations according to the geometric needs of the different metal ions [10-12]. The ligand 1,4-bis(1,2,4-triazol-1-yl)butane (BTB) as a long and flexible derivative of triazole, has been proven to be the good bridging ligands to construct novel coordination polymers [13-15]. Taking these into consideration, we explored the self-assembly of $\mathrm{Co}$ (II) and BTB and obtained a novel three-dimensional coordination polymer, $\left[\mathrm{Co}(\mathrm{BTB})_{3}\left(\mathrm{BF}_{4}\right)_{2}\right]_{\mathrm{n}}$ (1). Herein, we report the synthesis, crystal structure and magnetic properties.

\section{EXPERIMENTAL}

The 1,4-bis(1,2,4-triazol-1-yl)butane (BTB) ligand was prepared according to the previously reported procedure [16]. All other reagents and solvents used in the experiment were purchased from commercial sources and used without further purification. The $\mathrm{C}, \mathrm{H}$ and $\mathrm{N}$ elemental analysis were performed on a Vario EL III elemental analyzer. Infrared spectra were recorded from $\mathrm{KBr}$ pellets in the range 4000-400 $\mathrm{cm}^{-1}$ on a VECTOR 22 spectrometer. Thermal gravimetric analysis was performed on a Perkin-Elmer Pyris 1 TGA analyzer from 25 to $750{ }^{\circ} \mathrm{C}$ with a heating rate of $20^{\circ} \mathrm{C} \mathrm{min}^{-1}$ under nitrogen. The data of magnetic properties for crystalline samples were performed on a Quantum Design MPMP-XL7 superconducting quantum interference device (SQUID) magnetometer. Corrections of measured susceptibilities were made for both the sample holder as the background and the diamagnetism of the constituent atoms estimated from Pascal's constant [17].

X-ray crystallographic study of complex: Crystallographic diffraction data for complex $\mathbf{1}$ was recorded on a Siemens (Bruker) SMART CCD diffractometer using monochromated Mo $K_{\alpha}$ radiation $(\lambda=0.71073 \AA$ ) at $293 \mathrm{~K}$. Absorption correction was applied using multi-scan technique. The structure was solved by direct methods and refined with full-matrix leastsquares technique (SHELXTL-97) [18]. H atoms bonded to C atoms were placed in calculated positions and treated using a riding-model approximation, with $\mathrm{C}-\mathrm{H}=0.93$ (triazole) or $0.97 \AA$ (methylene) and $\mathrm{U}_{\text {iso }}(\mathrm{H})=1.2 \mathrm{U}_{\mathrm{eq}}(\mathrm{C})$. Fluorine atoms (F1 and F2) of complex $\mathbf{1}$ are disordered over two positions for which the site-occupation factors were 0.5 and 0.5 . The crystal data and structural refinement parameters of complex $\mathbf{1}$ are given in Table-1. Selected bond lengths and angles are given in Table-2. Supplementary material for structure $\mathbf{1}$ has been deposited with the Cambridge Crystallographic Data 


\begin{tabular}{|c|c|}
\hline \multicolumn{2}{|c|}{$\begin{array}{c}\text { TABLE-1 } \\
\text { CRYSTALLOGRAPHIC DATA AND } \\
\text { STRUCTURE REFINEMENT FOR COMPLEX } 1\end{array}$} \\
\hline Parameter & Value \\
\hline Formula weight & 809.26 \\
\hline $\mathrm{T}(\mathrm{K})$ & $293(2)$ \\
\hline Crystal system & Hexagonal \\
\hline Space group & $\mathrm{R}-3$ \\
\hline $\mathrm{a}(\AA)$ & $18.9673(12)$ \\
\hline b $(\AA)$ & $18.9673(12)$ \\
\hline c $(\AA)$ & $25.168(3)$ \\
\hline$\alpha\left({ }^{\circ}\right)$ & 90 \\
\hline$\beta\left({ }^{\circ}\right)$ & 90 \\
\hline$\gamma\left({ }^{\circ}\right)$ & 120 \\
\hline V & $7841.3(12)$ \\
\hline$\rho_{\text {calc }}\left(\mathrm{g} / \mathrm{cm}^{3}\right)$ & 1.542 \\
\hline $\mathrm{Z}$ & 9 \\
\hline $\mathrm{F}(000)$ & 3735 \\
\hline$\mu\left(\mathrm{mm}^{-1}\right)$ & 0.584 \\
\hline Crystal size (mm) & $0.21 \times 0.19 \times 0.17$ \\
\hline$\theta$ Range $\left(^{\circ}\right)$ & $2.04 \leq \theta \leq 25.07$ \\
\hline Index ranges $h, k, 1$ & $\begin{array}{l}-18 \leq \mathrm{h} \leq 22,-22 \leq \mathrm{k} \leq 17, \\
-25 \leq 1 \leq 30\end{array}$ \\
\hline Reflections collected & 13135 \\
\hline Independent reflections $\left(\mathrm{R}_{\text {in }}\right)$ & $3093(0.0557)$ \\
\hline Goodness of fit on $\mathrm{F}^{2}$ & 1.101 \\
\hline $\mathrm{R}$ indices $(\mathrm{I}>2 \sigma(\mathrm{I}))$ & $\mathrm{R}_{1}=0.0599, \mathrm{wR}_{2}=0.1729$ \\
\hline $\mathrm{R}$ indices (all data) & $\mathrm{R}_{1}=0.0694, \mathrm{wR}_{2}=0.1807$ \\
\hline$\Delta \rho_{\max } / \Delta \rho_{\min }\left(\mathrm{e} \AA^{-3}\right)$ & $1.090 /-0.461$ \\
\hline
\end{tabular}

\begin{tabular}{|c|c|c|c|}
\hline \multicolumn{4}{|c|}{$\begin{array}{c}\text { TABLE-2 } \\
\text { SELECTED BOND LENGTHS }(\AA) \text { AND } \\
\text { ANGLES }\left({ }^{\circ}\right) \text { FOR COMPLEX } 1\end{array}$} \\
\hline Bond & $\mathrm{d}(\AA)$ & Bond & $\mathrm{d}(\AA)$ \\
\hline $\operatorname{Co}(1)-\mathrm{N}(1)$ & $2.154(2)$ & $\operatorname{Co}(1)-\mathrm{N}(1)^{\mathrm{i}}$ & $2.154(2)$ \\
\hline $\mathrm{Co}(1)-\mathrm{N}(1)^{\mathrm{ii}}$ & $2.154(2)$ & $\mathrm{Co}(1)-\mathrm{N}(4)^{\mathrm{iii}}$ & $2.167(2)$ \\
\hline $\mathrm{Co}(1)-\mathrm{N}(4)^{\mathrm{iv}}$ & $2.167(2)$ & $\operatorname{Co}(1)-\mathrm{N}(4)^{\mathrm{v}}$ & $2.167(2)$ \\
\hline $\mathrm{Co}(2)-\mathrm{N}(9)$ & $2.140(4)$ & $\mathrm{Co}(2)-\mathrm{N}(9)^{\mathrm{i}}$ & $2.140(4)$ \\
\hline $\mathrm{Co}(2)-\mathrm{N}(9)^{\mathrm{ii}}$ & $2.140(4)$ & $\mathrm{Co}(2)-\mathrm{N}(9)^{\mathrm{vi}}$ & $2.140(4)$ \\
\hline $\mathrm{Co}(2)-\mathrm{N}(9)^{\mathrm{vii}}$ & $2.140(4)$ & $\mathrm{Co}(2)-\mathrm{N}(9)^{\mathrm{viii}}$ & $2.140(4)$ \\
\hline Angle & $\omega\left(^{\circ}\right)$ & Angle & $\omega\left(^{\circ}\right)$ \\
\hline $\mathrm{N}(1)-\mathrm{Co}(1)-\mathrm{N}(1)^{\mathrm{i}}$ & $90.78(9)$ & $\mathrm{N}(1)-\mathrm{Co}(1)-\mathrm{N}(1)^{\mathrm{ii}}$ & $90.78(9)$ \\
\hline $\mathrm{N}(1)-\mathrm{Co}(1)-\mathrm{N}(4)^{\mathrm{iii}}$ & $178.31(8)$ & $\mathrm{N}(1)-\mathrm{Co}(1)-\mathrm{N}(4)^{\mathrm{iv}}$ & $90.90(8)$ \\
\hline $\mathrm{N}(1)-\mathrm{Co}(1)-\mathrm{N}(4)^{\mathrm{v}}$ & $89.10(9)$ & $\mathrm{N}(1)^{\mathrm{i}}-\mathrm{Co}(1)-\mathrm{N}(1)^{\mathrm{ii}}$ & $90.78(9)$ \\
\hline $\mathrm{N}(1)^{\mathrm{i}}-\mathrm{Co}(1)-\mathrm{N}(4)^{\mathrm{iii}}$ & $89.10(9)$ & $\mathrm{N}(1)^{\mathrm{i}}-\mathrm{Co}(1)-\mathrm{N}(4)^{\mathrm{iv}}$ & $178.32(8)$ \\
\hline $\mathrm{N}(1)^{\mathrm{i}}-\mathrm{Co}(1)-\mathrm{N}(4)^{\mathrm{v}}$ & $90.90(8)$ & $\mathrm{N}(1)^{\mathrm{ii}}-\mathrm{Co}(1)-\mathrm{N}(4)^{\mathrm{iii}}$ & $90.91(8)$ \\
\hline $\mathrm{N}(1)^{\mathrm{ii}-\mathrm{Co}}(1)-\mathrm{N}(4)^{\mathrm{iv}}$ & $89.10(9)$ & $\mathrm{N}(1)^{\mathrm{ii}}-\mathrm{Co}(1)-\mathrm{N}(4)^{\mathrm{v}}$ & $178.32(8)$ \\
\hline $\mathrm{N}(4)^{\mathrm{iii}}-\mathrm{Co}(1)-\mathrm{N}(4)^{\mathrm{iv}}$ & $89.23(9)$ & $\mathrm{N}(4)^{\mathrm{iii}-}-\mathrm{Co}(1)-\mathrm{N}(4)^{\mathrm{v}}$ & $89.23(9)$ \\
\hline $\mathrm{N}(4)^{\mathrm{iv}}-\mathrm{Co}(1)-\mathrm{N}(4)^{\mathrm{v}}$ & $89.22(9)$ & $\mathrm{N}(9)-\mathrm{Co}(2)-\mathrm{N}(9)^{\mathrm{ii}}$ & $88.56(14)$ \\
\hline $\mathrm{N}(9)-\mathrm{Co}(2)-\mathrm{N}(9)^{\mathrm{vii}}$ & $180.000(1)$ & $\mathrm{N}(9)-\mathrm{Co}(2)-\mathrm{N}(9)^{\mathrm{viii}}$ & $91.44(14)$ \\
\hline $\mathrm{N}(9)^{\mathrm{i}}-\mathrm{Co}(2)-\mathrm{N}(9)$ & $88.56(14)$ & $\mathrm{N}(9)^{\mathrm{i}}-\mathrm{Co}(2)-\mathrm{N}(9)^{\mathrm{ii}}$ & $88.56(14)$ \\
\hline $\mathrm{N}(9)^{\mathrm{i}}-\mathrm{Co}(2)-\mathrm{N}(9)^{\mathrm{vi}}$ & $91.44(14)$ & $\mathrm{N}(9)^{\mathrm{i}}-\mathrm{Co}(2)-\mathrm{N}(9)^{\mathrm{vii}}$ & $91.44(14)$ \\
\hline $\mathrm{N}(9)^{\mathrm{i}}-\mathrm{Co}(2)-\mathrm{N}(9)^{\mathrm{viii}}$ & $180.000(1)$ & $\mathrm{N}(9)^{\mathrm{ii}}-\mathrm{Co}(2)-\mathrm{N}(9)^{\mathrm{vii}}$ & $91.44(14)$ \\
\hline $\mathrm{N}(9)^{\mathrm{ii}}-\mathrm{Co}(2)-\mathrm{N}(9)^{\mathrm{viii}}$ & $91.44(14)$ & $\mathrm{N}(9)^{\mathrm{vi}}-\mathrm{Co}(2)-\mathrm{N}(9)$ & $91.44(14)$ \\
\hline $\mathrm{N}(9)^{\mathrm{vi}}-\mathrm{Co}(2)-\mathrm{N}(9)^{\mathrm{ii}}$ & $180.000(1)$ & $\mathrm{N}(9)^{\mathrm{vi}}-\mathrm{Co}(2)-\mathrm{N}(9)^{\mathrm{vii}}$ & $88.56(14)$ \\
\hline $\mathrm{N}(9)^{\mathrm{vi}}-\mathrm{Co}(2)-\mathrm{N}(9)^{\mathrm{viii}}$ & $88.56(14)$ & $\mathrm{N}(9)^{\mathrm{vii}}-\mathrm{Co}(2)-\mathrm{N}(9)^{\mathrm{viii}}$ & $88.56(14)$ \\
\hline \multicolumn{4}{|c|}{$\begin{array}{l}\text { Symmetry codes: (i) -x+y, }-\mathrm{x}, \mathrm{z} \text {; (ii) }-\mathrm{y}, \mathrm{x}-\mathrm{y}, \mathrm{z} \text {; (iii) } \mathrm{x}-2 / 3, \mathrm{y}-1 / 3, \mathrm{z}-1 / 3 \text {; } \\
\text { (iv) -x+y+1/3, -x+2/3, z-1/3; (v) -y+1/3, x-y-1/3, z-1/3; (vi) } \mathrm{y},-\mathrm{x}+\mathrm{y} \text {, } \\
-\mathrm{z}+2 \text {; (vii) }-\mathrm{x},-\mathrm{y},-\mathrm{z}+2 \text {; (viii) } \mathrm{x}-\mathrm{y}, \mathrm{x},-\mathrm{z}+2 \text {. }\end{array}$} \\
\hline
\end{tabular}

Centre (CCDC no. 981078; deposit@ ccdc. cam. ac. uk or http:/ /www.ccdc.Cam.ac.uk).
Synthesis of the complex $\left[\mathrm{Co}(\mathrm{BTB})_{3}\left(\mathrm{BF}_{4}\right)_{2}\right]_{\mathbf{n}}(1)$ : A mixture of $\mathrm{CH}_{3} \mathrm{CN}$ and $\mathrm{H}_{2} \mathrm{O}(\mathrm{v} / \mathrm{v}, 5: 1,10 \mathrm{~mL})$ was gently layered on the top of a mixture of $\mathrm{CH}_{3} \mathrm{CN}$ and $\mathrm{H}_{2} \mathrm{O}$ (v/v, 2:1, $3 \mathrm{~mL}$ ) containing $\mathrm{Co}\left(\mathrm{BF}_{4}\right)_{2} \cdot 6 \mathrm{H}_{2} \mathrm{O}(0.0341 \mathrm{~g}, 0.100 \mathrm{mmol})$. A solution of the ligand BTB $(0.0577 \mathrm{~g}, 0.300 \mathrm{mmol})$ in $3 \mathrm{~mL}$ of $\mathrm{CH}_{3} \mathrm{CN}$ was added carefully as a third layer. Red block crystals of complex 1 were obtained after 3 weeks (yield $21.3 \%$, based on Co). Elemental analysis for $\mathrm{C}_{24} \mathrm{H}_{36} \mathrm{~N}_{18} \mathrm{~F}_{8} \mathrm{~B}_{2} \mathrm{Co}(\mathrm{Mw}=809.26)$ : C, 35.62; H, 4.48; N, 31.16 \%; found: C, 35.71; H, 4.49; N $31.25 \%$. IR (KBr, cm $\left.{ }^{-1}\right)$ : 3139(s), 2964(w), 2861(w), 1545(s), 1529(s), 1453(s), 1267(s), 1123(w), 665(s).

\section{RESULTS AND DISCUSSION}

$\mathrm{X}$-ray structural analysis revealed that complex $\mathbf{1}$ is composed of 3D $\alpha$-polonium cubic networks with triple interpenetrating $\left[\mathrm{Co}(\mathrm{BTB})_{3}\right]^{2+}$ macrocations and non-coordinated tetrafluoroborate anions. Complex 1 crystallizes in the hexagonal space group R-3 and the asymmetric unit consists of two parts and one tetrafluoroborate. Part 1 contains one $\mathrm{Co} 1$ ion and one complete BTB-A ligand (BTB-A: N1-N6/C1-C8), while part 2 contains one $\mathrm{Co} 2$ ion and half of the other BTB-B ligand (BTB-B: N7-N9/C9-C12). The site occupation factors of Co1 and $\mathrm{Co} 2$ ions are $1 / 3$ and 1/6, respectively. As shown in Fig. 1, both $\mathrm{Co} 1$ and $\mathrm{Co} 2$ atoms are coordinated by six nitrogen atoms from six different BTB ligands to give distorted $\mathrm{CoN}_{6}$ octahedron geometries. The bond distances and angles around Co(II) ions are 2.140(4)-2.167(2) $\AA$ for Co-N and 88.56(14)$180.000(1)^{\circ}$ for $\mathrm{N}-\mathrm{Co}-\mathrm{N}$, which are similar to other Co-based complexes $[19,20]$.

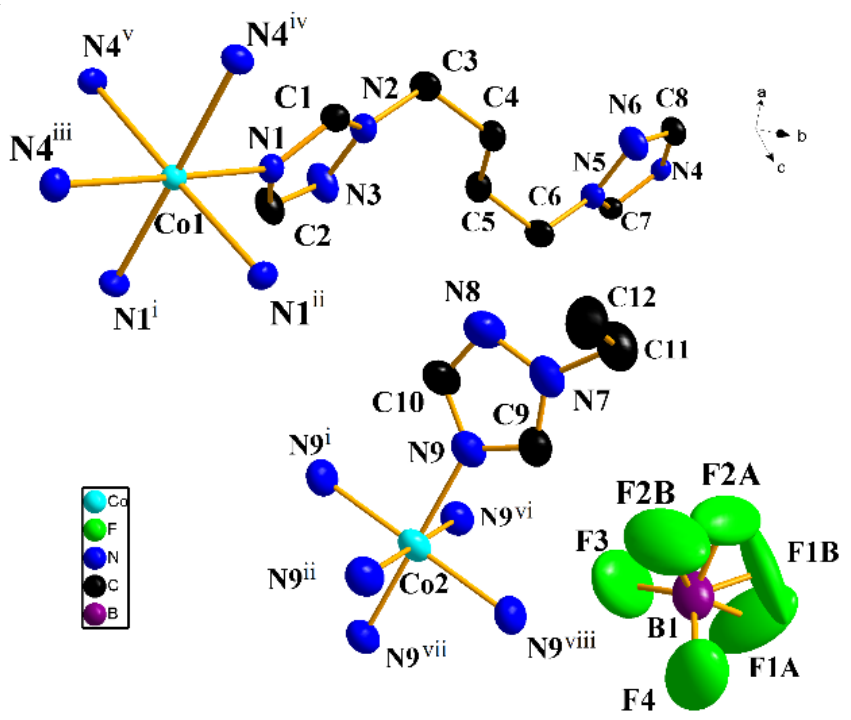

Fig. 1. A view of the local coordination of the Co(II) cations in complex 1, showing the atom-numbering scheme. Displacement ellipsoids are drawn at the $30 \%$ probability level. Hydrogen atoms have been omitted for clarity. [Symmetry codes: $\mathrm{i}-\mathrm{x}+\mathrm{y},-\mathrm{x}, \mathrm{z}$; ii $-\mathrm{y}, \mathrm{x}-\mathrm{y}, \mathrm{z}$; iii $\mathrm{x}-2 / 3, \mathrm{y}-1 / 3, \mathrm{z}-1 / 3$; iv $-\mathrm{x}+\mathrm{y}+1 / 3,-\mathrm{x}+2 / 3, \mathrm{z}-1 / 3$; v $-\mathrm{y}+1 / 3, \mathrm{x}-\mathrm{y}-1 / 3$, $\mathrm{z}-1 / 3$; vi $\mathrm{y},-\mathrm{x}+\mathrm{y},-\mathrm{z}+2$; vii $-\mathrm{x},-\mathrm{y},-\mathrm{z}+2$; viii $\mathrm{x}-\mathrm{y}, \mathrm{x},-\mathrm{z}+2]$

In complex 1, the dihedral angle between the two triazole rings is $171.3^{\circ}$ for BTB-A ligand, while the corresponding angle in BTB-B ligand is $180.0^{\circ}$. The BTB-A ligand adopts a gauche-trans-gauche conformation to bridge two Co1 atoms with a Co1 …Co1 distance of 13.7949(9) A. Similarly, neigh- 
boring $\mathrm{Co} 2$ atoms are conjoined via tethering BTB-B ligands, in which the BTB-B shows a trans-trans-trans conformation, with a Co2 $\cdots$ Co2 distance of 13.7949(9) A. Surprisingly, although the BTB ligands adopt different conformations, the Co $\cdots$ Co separations in the two parts are the same. In complex 1, the six connected $\mathrm{Co}$ (II) nodes are connected by six linear BTB ligands extending into an open 3D network with $\alpha$-polonium topology (Fig. 2). Interestingly, there are two independent but quite similar such $3 \mathrm{D}$ cubic networks (A and B) in complex $\mathbf{1}$ as shown in Fig. 3.

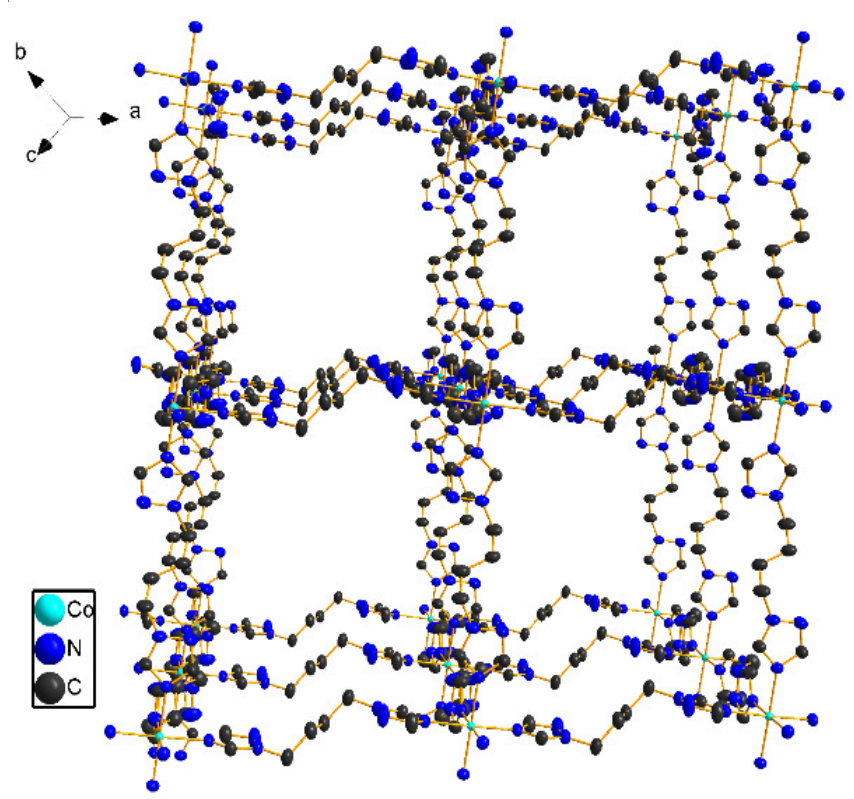

Fig. 2. View of the 3D $\alpha$-polonium cubic network in complex 1. Hydrogen atoms and tetrafluoroborate are omitted for clarity

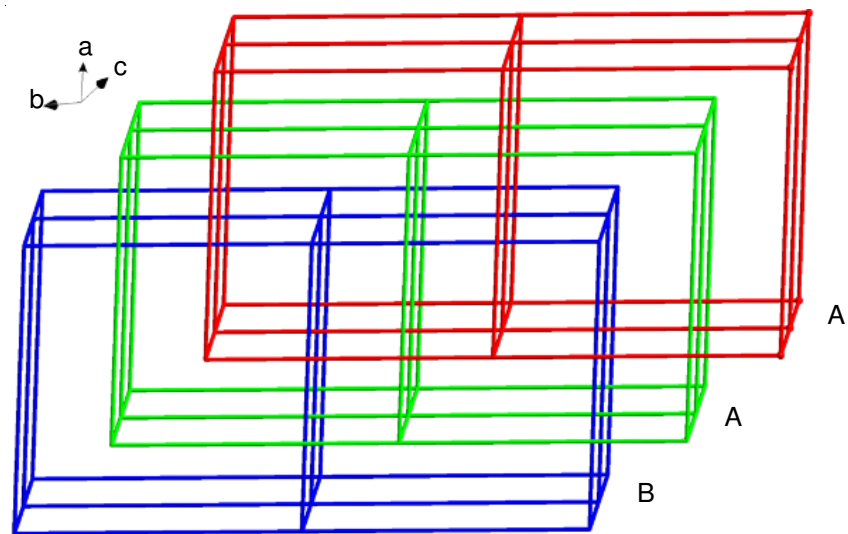

Fig. 3. Schematic representation of the 3 -fold interpenetrating framework in complex 1

The Co1 nodes are connected by BTB-A ligands to form type A networks, while the adjacent $\mathrm{Co} 2$ atoms are conjoined via tethering BTB-B ligands to form type B networks. In order to stabilize the framework, the type A networks interpenetrate, leading to the formation of an unusual twofold interpenetrating three-dimensional architecture. Two-fold interpenetrated type A networks and type B networks interlock with each other to form 3-fold interpenetrating cubic networks. Furthermore, channels with dimensions of approximately $19 \times 20 \AA$ are formed, which are filled by $\mathrm{BF}_{4}^{-}$anions (Fig. 4).

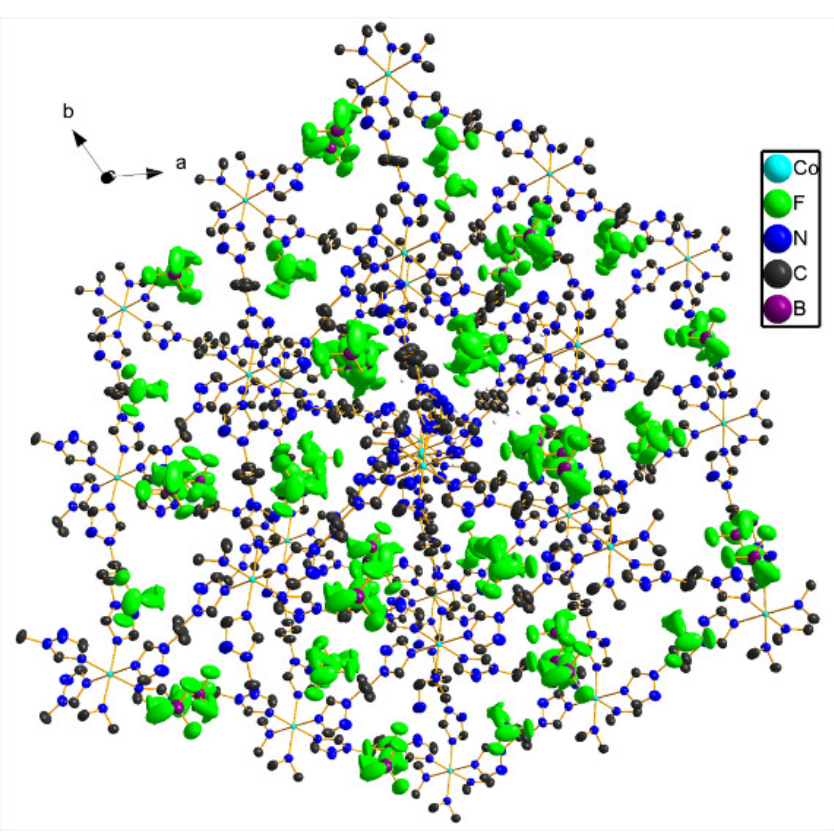

Fig. 4. View of the 3D $\alpha$-polonium cubic network in complex $\mathbf{1}$ along the c axis

To verify the thermal stability of complex $\mathbf{1}$, thermogravimetric analysis was carried out. As shown in Fig. 5, the decomposition of the organic ligand is observed from 275 to $400{ }^{\circ} \mathrm{C}$. The remaining weight corresponds to the formation of $\mathrm{CoO}$ (obsd. $9.25 \%$, calcd. $9.26 \%$ ).

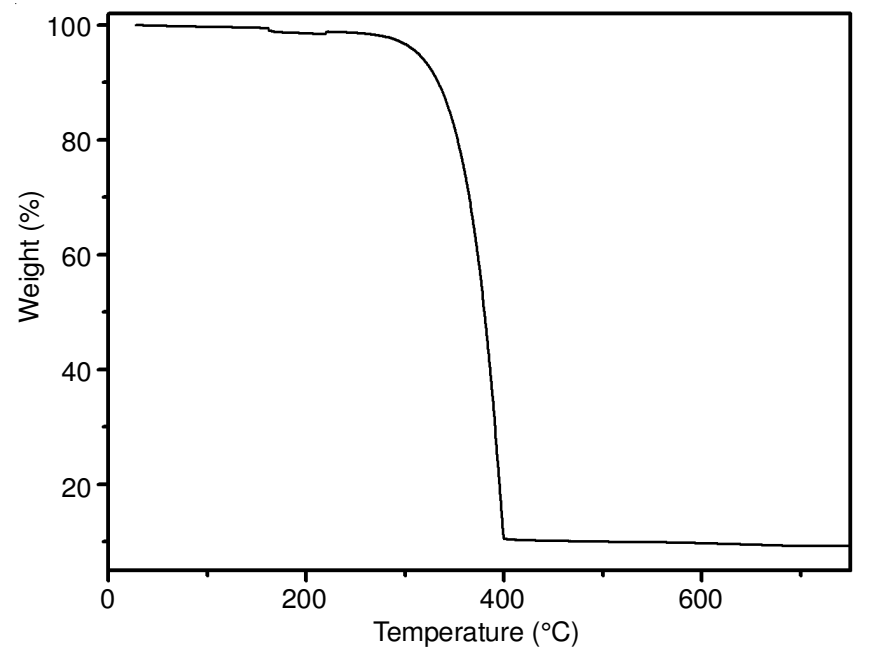

Fig. 5. Thermogravimetric curve of complex $\mathbf{1}$

Variable-temperature magnetic measurements were performed on polycrystalline samples of complex 1 in the range of 1.8 to $300 \mathrm{~K}$ in $2 \mathrm{kOe}$. As shown in Fig. 6 , the $\chi_{\mathrm{M}} \mathrm{T}$ value at the room temperature is $2.84 \mathrm{~cm}^{3} \mathrm{~K} \mathrm{~mol}^{-1}$ which is much larger than the spin-only value of of $1.88 \mathrm{emu} \mathrm{mol}^{-1} \mathrm{~K}$ for isolated $\mathrm{Co}$ (II) systems assuming $\mathrm{g}=2$. This is due to the significant orbital contribution of the octahedral $\mathrm{Co}$ (II) ions. As the temperature decreases, $\chi_{M} \mathrm{~T}$ value gradually decreases and reaches a minimum of $2.05 \mathrm{~cm}^{3} \mathrm{~K} \mathrm{~mol}^{-1}$ at $1.8 \mathrm{~K}$. The decrease of $\chi_{M} \mathrm{~T}$ is mainly ascribed to the spin-orbit coupling effects, showing the single-ion behaviour of the cobalt(II) centers in complex 1 [21,22]. 


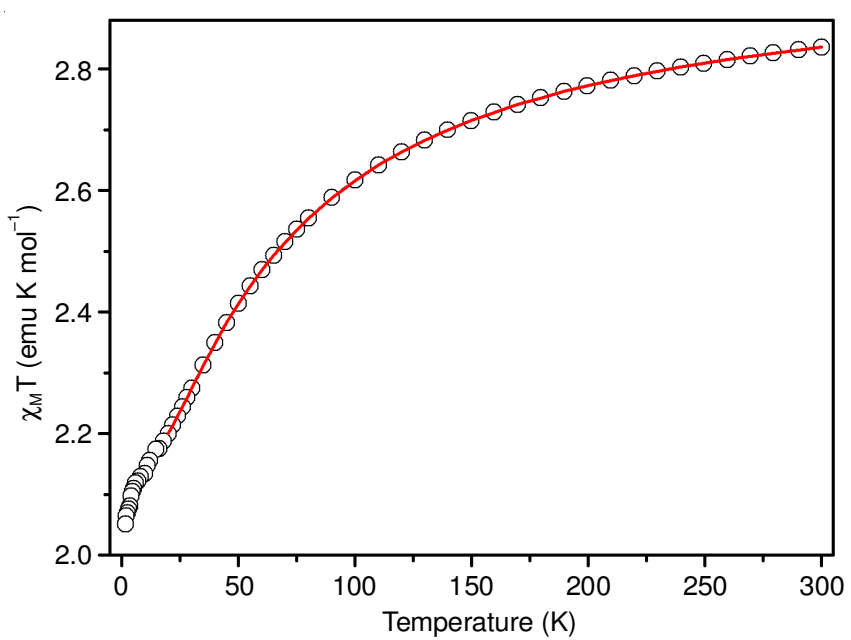

Fig. 6. Plot of $\chi_{\mathrm{M}} \mathrm{T}$ versus $\mathrm{T}$ for complex $\mathbf{1}$ at $\mathrm{H}=2 \mathrm{kOe}$. The line represents the best fit

To investigate the magnetic properties, the simple phenomenological equation and the fitting method therein can be used for roughly estimating the spin-orbit coupling and the magnetic exchange of complex $\mathbf{1}$ in the lower temperature range [23-25]. The magnetic data were roughly fitted with the simple phenomenological equation:

$$
\chi_{\mathrm{M}} \mathrm{T}=\mathrm{A} \exp \left(-\mathrm{E}_{1} / \mathrm{kT}\right)+\mathrm{B} \exp \left(-\mathrm{E}_{2} / \mathrm{kT}\right)
$$

where $\mathrm{A}+\mathrm{B}, \mathrm{E}_{1}$ and $\mathrm{E}_{2}$ have the same meanings as in the literatures and other symbols have their usual meanings. The best fitting results (the solid) are: $\mathrm{A}+\mathrm{B}=3.01 \mathrm{~cm}^{3} \mathrm{~K} \mathrm{~mol}^{-1}$, $\mathrm{E}_{1} / \mathrm{k}=56.5 \mathrm{~K}$ corresponding to one $\mathrm{Co}(\mathrm{II})$ ion and $-\mathrm{E}_{2} / \mathrm{k}=$ $-0.26 \mathrm{~K}\left(\mathrm{R}=2.9 \times 10^{-4}\right)$ (Fig. 6), indicating the antiferromagnetic coupling between $\mathrm{Co}(\mathrm{II})$ ions $(J=-0.52 \mathrm{~K})$. Comparing to the spin-orbit coupling, the $J$ value is so small that could be neglected.

\section{Conclusion}

In summary, one coordination polymer based on 1,4-bis(1,2,4-triazol-1-yl)butane has been prepared and characterized through IR, elemental analysis, thermal analysis and singlecrystal X-ray diffraction. The crystal structure of complex $\mathbf{1}$ shows a 3 -fold interpenetrating $\alpha$-polonium cubic network. In addition, complex $\mathbf{1}$ exhibits very weak antiferromagnetic coupling between $\mathrm{Co}(\mathrm{II})$ ions in low temperature.

\section{ACKNOWLEDGEMENTS}

The authors are grateful for financial support from the Natural Science Foundation of the Jiangsu Higher Education Institutions of China (15KJB150030), a Project Funded by the Excellent Specialties Program Development of Jiangsu Higher Education Institutions (PPZY2015B113) and the Natural Science Foundation of Yancheng Teachers University.

\section{REFERENCES}

1. R. Krishna, Chem. Soc. Rev., 41, 3099 (2012); https://doi.org/10.1039/c2cs15284c.
2. A. Laguna, T. Lasanta, J. Lopezde-Luzuriaga, M. Monge, P. Naumov and M.E. Olmos, J. Am. Chem. Soc., 132, 456 (2010); https://doi.org/10.1021/ja909241m.

3. S. Alghool and C. Slebodnick, J. Inorg. Organomet. Polym., 24, 644 (2014); https://doi.org/10.1007/s10904-014-0028-X.

4. Z.Z. Lu, R. Zhang, Y.Z. Li, Z.-J. Guo and H.-G. Zheng, J. Am. Chem. Soc., 133, 4172 (2011); https://doi.org/10.1021/ja109437d.

5. K. Sumida, D.L. Rogow, J.A. Mason, T.M. McDonald, E.D. Bloch, Z.R. Herm, T.-H. Bae and J.R. Long, Chem. Rev., 112, 724 (2012); https://doi.org/10.1021/cr2003272.

6. C. Train, T. Nuida, R. Gheorghe, M. Gruselle and S. Ohkoshi, J. Am. Chem. Soc., 131, 16838 (2009); https://doi.org/10.1021/ja9061568.

7. T.R. Cook, Y.R. Zheng and P.J. Stang, Chem. Rev., 113, 734 (2013); https://doi.org/10.1021/cr3002824.

8. F.A. Almeida Paz, J. Klinowski, S.M.F. Vilela, J.P.C. Tomé, J.A.S. Cavaleiro and J. Rocha, Chem. Soc. Rev., 41, 1088 (2012); https://doi.org/10.1039/C1CS15055C.

9. Y. Yang, J. Yang, P. Du, Y.-Y. Liu and J.-F. Ma, CrystEngComm, 16, 1136 (2014); https://doi.org/10.1039/C3CE42048E.

10. Y.F. Peng, S. Zhao, K. Li, L. Liu, B.-L. Li and B. Wu, CrystEngComm, 17, 2544 (2015); https://doi.org/10.1039/C4CE02465F

11. J.G. Ding, X. Zhu, Y.F. Cui, N. Liang, P.-P. Sun, Q. Chen, B.-L. Li and H.-Y. Li, CrystEngComm, 16, 1632 (2014); https://doi.org/10.1039/c3ce42189a.

12. J. Wang, Bull. Korean Chem. Soc., 35, 1529 (2014); https://doi.org/10.5012/bkcs.2014.35.5.1529.

13. J. Wang, X.J. Xu and J.Q. Tao, Acta Crystallogr. C, 67, m137 (2011); https://doi.org/10.1107/S0108270111011413.

14. X. Zhu, L.Y. Wang, X.G. Liu, J. Wang, B.-L. Li and H.-Y. Li, CrystEngComm, 13, 6090 (2011); https://doi.org/10.1039/c1ce05466j.

15. L.Y. Wang, Y. Yang, K. Liu, B.-L. Li and Y. Zhang, Cryst. Growth Des., 8, 3902 (2008); https://doi.org/10.1021/cg800484k.

16. X.G. Liu, Y.M. Zhang and B.L. Li, J. Suzhou Univ. (Natural Sci.), 21, 59 (2005).

17. O. Kahn, Molecular Magnetism, VCH Publishers, New York (1993).

18. SHELXTL Bruker, Structure Determination Software Programs; Bruker Analytical X-ray Instruments Inc.: Madison, Wisconsin, USA (1997).

19. B. Liu, J. Shi, K.F. Yue, D.-S. Li and Y.-Y. Wang, Cryst. Growth Des., 14, 2003 (2014); https://doi.org/10.1021/cg500121f.

20. X. Lv, L. Liu, C. Huang, L. Guo, J. Wu, H. Hou and Y. Fan, Dalton Trans., 43, 15475 (2014); https://doi.org/10.1039/C4DT02342K.

21. M.J. Plater, M.R. Foreman, E. Coronado, C.J. Gómez-Garcia and A.M.Z. Slawin, J. Chem. Soc., Dalton Trans., 4209 (1999); https://doi.org/10.1039/a905332h.

22. J. Wang, Y.L. Xu, H.B. Zhou, H.-S. Wang, X.-J. Song, Y. Song and X.-Z. You, Dalton Trans., 39, 3489 (2010); https://doi.org/10.1039/b924203a.

23. P. Rabu, J.M. Rueff, Z.L. Huang, S. Angelov, J. Souletie and M. Drillon, Polyhedron, 20, 1677 (2001); https://doi.org/10.1016/S0277-5387(01)00672-6.

24. J.M. Rueff, N. Masciocchi, P. Rabu, A. Sironi and A. Skoulios, Eur. J. Inorg. Chem., 2843 (2001); https://doi.org/10.1002/1099-0682(200111)2001:11<2843::AID-EJIC 2843>3.0.CO;2-T.

25. J.-M. Rueff, N. Masciocchi, P. Rabu, A. Sironi and A. Skoulios, Chem. Eur. J., 8, 1813 (2002); https://doi.org/10.1002/1521-3765(20020415)8:8<1813::AID-CHEM $1813>3.0 . \mathrm{CO} ; 2-\mathrm{G}$. 